\title{
Floral Colonization Dynamics and Specificity of Aureobasidium pullulans Strains Used to Suppress Fire Blight of Pome Fruit
}

\author{
T. N. Temple ${ }^{1}$, E. C. Thompson ${ }^{1}$, S. Uppala ${ }^{1}$, D. Granatstein ${ }^{2}$, and K. B. Johnson ${ }^{1, \dagger}$ \\ ${ }^{1}$ Oregon State University, Department of Botany and Plant Pathology, Corvallis, OR 97331 \\ ${ }^{2}$ Washington State University, Tree Fruit Research and Extension Center, Wenatchee, WA 98801
}

\begin{abstract}
Aureobasidium pullulans is used as a biocontrol agent for fire blight protection in organic apple and pear production. We assessed colonization of pome flowers by A. pullulans in orchards located near Corvallis, OR and Wenatchee, WA. Blossom Protect, a mix of A. pullulans strains CF10 and CF40, and its citrate-based companion, Buffer Protect, were sprayed at $70 \%$ bloom. Later in bloom, the population size of putative A. pullulans on flowers was estimated by dilution plating; plate scrapings of putative A. pullulans were then sampled and subjected to a PCR analysis. Sequenced PCR amplicons of the internal transcribed spacer region and the elongase gene confirmed the presence of A. pullulans, whereas a multiplex PCR with primers specific to CF10 and CF40 was used to determine the presence of the introduced strains. At Corvallis, a wet spring environment, A. pullulans, was recovered from most (>90\%) Bartlett pear and Golden Delicious apple flowers sampled from experimental trees, regardless of whether the trees were treated with Blossom Protect. Nevertheless, population size estimates of A. pullulans on the flowers

but only on a minority of flowers from nontreated controls. In both locations, the combined incidence of strains CF10 and CF40 on flowers averaged $89 \%$ on Blossom Protect-treated trees, but only $27 \%$ on adjacent, nontreated trees. During subsequent trials, the efficacy of Blossom Protect for fire blight control was compared with alternative yeast isolates, with each applied with Buffer Protect; local isolates of $A$. pullulans and Cryptococcus neoformans and a postharvest biocontrol strain of $C y s$ tofilobasidium infirmominiatum were used All yeast strains suppressed fire blight to a degree; however, in each of four trials, the level of suppression was highest with Blossom Protect, and it was significantly superior $(P \leq 0.05)$ to other yeast isolates in two of the trials. Because $A$. pullulans strains CF10 and CF40 were detected primarily on flowers on trees treated with Blossom Protect, and because they were detected much less frequently on nearby nontreated tress, we recommend treating every tree row with Blossom Protect at least once for organic fire blight suppression.
\end{abstract} were correlated with the number of times Blossom Protect was sprayed on the trees. At Wenatchee, an arid spring environment, A. pullulans was detected on most flowers from trees treated with Blossom Protect,
Keywords: cultural and biological practices, disease management, fruit, tree fruits
Fire blight, caused by the bacterium Erwinia amylovora, is a destructive disease to which most widely planted commercial apple and pear cultivars are susceptible (Van der Zwet and Beer 1995). In addition to sanitation, fire blight suppression requires sprays of inhibitory materials during bloom, when the pathogen greatly increases its population size by growing epiphytically on flowers (Thomson 2000). In the United States, antibiotics (e.g., streptomycin) are the most common materials used to protect pome flowers from infection by E. amylovora. Since 2014, however, antibiotics have been prohibited in certified organic orchards, which occupy 9,000 ha in the western United States, mostly Washington State. In response, many organic orchardists have adopted "integrated" spray programs that utilize nonantibiotic materials in a specific sequence to target phases of pathogen activity during bloom (Johnson and Temple 2013; Johnson et al. 2014). Typically, these programs utilize a biological agent early in bloom, followed by nonantibiotic chemicals (e.g., copper sulfate) later in bloom. The most widely adopted biological material is a product named Blossom Protect (Westbridge Agricultural Products, Vista, CA), which consists of two strains (CF10 and CF40) of the common yeast Aureobasidium pullulans (Kunz 2004; Loncaric et al. 2008), which is sprayed with an acidic buffer named

${ }^{\dagger}$ Corresponding author: K. B. Johnson; johnsonk@science.oregonstate.edu

Funding: This work was funded by the USDA NIFA Organic Transitions Program (award 2014-51106-22079) and the Washington Tree Fruit Research Commission.

The author(s) declare no conflict of interest.

Accepted for publication 26 July 2019.

(C) 2020 The American Phytopathological Society
Buffer Protect (Westbridge Agricultural Products), which is $43 \%$ citrate and $23 \%$ disodium phosphate plus inerts. Blossom Protect and Buffer Protect have shown outstanding efficacy against fire blight (Johnson and Temple 2013; Kunz et al. 2008); therefore, they are foundational materials for organic orchards in the western United States.

Originally, A. pullulans strains CF10 and CF40 were selected for their ability to suppress postharvest fungal fruit rots of apple (Leibinger et al. 1997); only later were they screened for fire blight control by Kunz (2004). In 2009, fire blight control trials were begun to evaluate Blossom Protect in the United States (Johnson and Temple 2013), which was registered by the Environmental Protection Agency (EPA) and approved by the United States Department of Agriculture (USDA) National Organic Program in 2012. With indirect initial selection and a short history of use in commercial orchards, little was known about how $A$. pullulans suppresses fire blight, including the dynamics of floral colonization, the population size of the antagonist that protects a flower, and the specificity of CF10 and CF40 for disease control. Apple and pear flowers open sequentially with bloom periods of 7 to 20 days, but individual flowers susceptible to E. amylovora have bloom periods of only 3 to 8 days (Pusey and Smith 2008; Thomson 2000). Gram-negative bacteria have been shown to antagonize E. amylovora on flowers (e.g., Pantoea agglomerans or Pseudomonas fluorescens). Previous studies (Johnson et al. 2000; Lindow and Suslow 2003) found that these antagonists colonize flowers that open after spray treatment, and that this dispersal can be a substantial but variable component of disease suppression (Nuclo et al. 1998). Consequently, the colonization dynamics of an introduced microbe have practical implications for the treatment strategy (e.g., spraying every row versus spraying alternate rows).

This study quantified pome flower colonization by A. pullulans after treatment with Blossom Protect. The incidence and population size of A. pullulans on individual flowers were measured on treated and nontreated trees, and a PCR-based assay was performed to 
determine if isolates $\mathrm{CF} 10$ and $\mathrm{CF} 40$ from Blossom Protect were present on the flowers. Experiments were conducted at two locations representing a wet spring climate (Corvallis, OR) and an arid spring climate (Wenatchee, WA). Subsequently, the specificity of CF10 and CF40 for fire blight control were compared with those other yeasts with the ability to grow epiphytically on pome flowers.

\section{Materials and Methods}

Preliminary analyses. Specific detection of $A$. pullulans isolates CF10 and CF40 on field-grown pear and apple flowers was assessed with a strain-specific, multiplex PCR reaction adapted from the work of Loncaric et al. (2008) (Table 1). This group concluded that CF10 and CF40 could be detected in environmental samples with primer sets SCAR6 and SCH3RAPD, respectively, but few data beyond the assay results of $A$. pullulans-treated flowers grown in a greenhouse were provided. Consequently, we conducted preliminary experiments to evaluate the PCR protocol and to develop a protocol for processing pear and apple flower samples from an orchard. In all experiments described, A. pullulans was cultured in 9-cm Petri dishes on one-half-strength potato dextrose agar (Difco, Becton Dickinson, Franklin Lakes, NJ) amended with Bacto agar (7.5 g/liter) and streptomycin sulfate $(100 \mu \mathrm{g} / \mathrm{ml})$ (PDA) (Johnson and Temple 2013).

Initially, we evaluated three methods of DNA extraction from $A$. pullulans scraped from PDA with a flamed culture loop and suspended in $1 \mathrm{ml}$ of sterile deionized water (SDW): DNeasy Plant Mini Kit (Qiagen, Germantown, MD), InstaGene Matrix (Biorad, Hercules, CA), and boiling in SDW for $5 \mathrm{~min}$. To determine proportions of $\mathrm{CF} 10$ and $\mathrm{CF} 40$ in commercial packages of Blossom Protect, we plated serial 10 -fold dilutions of 0.1 -g aliquots of product suspended in SDW on PDA. From these plates, we randomly selected a total of 36 single-colony isolates of A. pullulans (12 from each of three packages). In addition, to verify stability of the PCR markers for each strain, we made 10 sequential transfers of the single-colony isolates to PDA ( $\approx 50$ days to complete the 10 sequential transfers). We subjected the isolates to the multiplex PCR analysis after the first, fifth, and tenth transfers. Then, we evaluated two additional primer sets to aid in the identification of putative A. pullulans isolates from field samples (Table 1). One primer set amplified the internal transcribed spacer region (ITS) (White et al. 1990), and the other amplified a portion of the elongase gene, ELO2 (Zalar et al. 2008). PCR amplicons from primers ITS and ELO2 were cleaned with ExoSapIT (Affymetrix, Santa Clara, CA) and sequenced at the Center for Genome Research and Biocomputing at Oregon State University. Species identities of sequenced PCR products were obtained by referencing the National Center for Biotechnology Information
BLAST nucleotide database (U.S. National Institutes of Health, Bethesda, MD).

Finally, in Spring 2015, we sampled pear and apple flowers from trees sprayed with Blossom Protect plus Buffer Protect and with water for the purpose of evaluating a PCR protocol for detecting the presence of strains CF10 and CF40 on flowers. The trees were in orchards located at the Oregon State University Botany and Plant Pathology Field Laboratory near Corvallis, OR, and they were part of larger fire blight suppression trials. Within the two pear orchards (0.5-ha blocks of Pyrus communis L. cv. Bartlett on OHxF 97 or seedling rootstock, 15 and 56 years old in 2015, and spaced $6 \times$ $6 \mathrm{~m}$ between and within rows), a total of 28 of 82 (15-year-old) trees and a total of 8 of 70 (56-year-old) trees in the blocks were treated with Blossom Protect. In the apple orchard (a 0.4-ha block of Malus $\times$ domestica Borkh cv. Golden Delicious on EMLA 26 rootstock, 35 years old, and spaced 6 by $6 \mathrm{~m}$ ), 24 of 65 trees in the block were treated with Blossom Protect. In each orchard, the trees selected for sampling (a total of four) had been treated at $80 \%$ bloom with Blossom Protect plus Buffer Protect (maximum labeled rates of 1.6 and $11.2 \mathrm{~g} /$ liter, respectively; 3 liters per tree), with a corresponding sample of flowers from trees sprayed with water only. At 1-week after treatment (near petal-fall), a total of 24 whole flowers per orchard were randomly sampled from trees of each treatment (6 to 7 flowers per replicate tree) and immediately placed individually in wells of a microtiter dish. In the laboratory, sampled flowers were washed individually in test tubes containing $1 \mathrm{ml}$ of SDW and sonicated for 3 min. After vortexing, $10-\mu l$ samples of the flower wash and two 1: 100 dilutions were spread on PDA. Colonies with size and morphology consistent with A. pullulans were counted after 3 days of incubation at $20^{\circ} \mathrm{C}$. Then, two methods of sampling putative $A$. pullulans for PCR analysis were compared. Using one method, we scraped an apparently single colony off a dilution plate with a flamed bacterial culture loop and transferred the cells to $0.2 \mathrm{ml}$ of SDW. Using the other method, we scraped the loop through as many putative $A$. pullulans colonies on a plate as possible before transferring the biomass on the loop to SDW.

Orchard experiments in 2016. Colonization of pear and apple flowers by A. pullulans after treatment with Blossom Protect was evaluated in replicated trials in orchards at locations selected to contrast the expected amount of rainfall during bloom (Corvallis, OR, with an average April rainfall of $74 \mathrm{~mm}$; Wenatchee, WA, with an average April rainfall of $13 \mathrm{~mm}$ ). At Corvallis, experiments were established for the 57-year-old 'Bartlett' pear and 36-year-old 'Golden Delicious' apple orchard blocks used in the preliminary sampling experiment. Treatments were as follows: i) water-treated control; ii) Blossom Protect plus Buffer Protect at $70 \%$ bloom (previously mentioned rates); iii) Buffer Protect only at $70 \%$ bloom;

Table 1. PCR primers used in this study to identify field isolates of Aureobasidium pullulans to species ${ }^{\mathrm{a}}$ and to identify A. pullulans strains CF10 and CF40, which are specific to the fire blight control product, Blossom Protect ${ }^{\mathrm{b}}$

\begin{tabular}{|c|c|c|c|c|}
\hline Primer set & Sequence $\left(5^{\prime}\right.$ to $\left.3^{\prime}\right)$ & Conditions $^{\mathrm{c}}$ & Specificity & Product size \\
\hline ITS1-F & CTTCGTCATTTAGAGGAAGTAA & $55^{\circ} \mathrm{C} ; 30 \mathrm{~s}(35 \mathrm{X})$ & A. pullulans & $520 \mathrm{bp}$ \\
\hline ITS4-R & TCCTCCGCTTATTGATATGC & & internal transcribed spacer region ${ }^{\mathrm{d}}$ & \\
\hline ELO2-F & CACTCTTGACCGTCCCTTCGG & $56^{\circ} \mathrm{C} ; 60 \mathrm{~s}(30 \mathrm{X})$ & A. pullulans & 704 bp \\
\hline ELO2-R & GCGGTGATGTACTTCTTCCACCAG & & elongase gene $e^{e}$ & \\
\hline SCAR6-F & TGCCGACTACGGTGTATGAGCTTACATCAA & $68^{\circ} \mathrm{C} ; 30 \mathrm{~s}(35 \mathrm{X})$ & A. pullulans strain $\mathrm{CF} 10^{\mathrm{f}}$ & $307 \mathrm{bp}$ \\
\hline SCAR6-R & GTTACAACCGCTAATCATCTTTAGTGCCCCGGA & $\begin{array}{l}21 \text { st cycle: add extension of } \\
72^{\circ} \mathrm{C} ; 60 \mathrm{~s} \text { with increments } \\
\text { of } 5 \mathrm{~s} \text { for each cycle }(15 \mathrm{X})\end{array}$ & & \\
\hline SCH3RAPD-F & TGCCGACTACCAGGCGATACTTTTTAACT & $68^{\circ} \mathrm{C} ; 30 \mathrm{~s}(35 \mathrm{X})$ & A. pullulans, strain $\mathrm{CF} 40^{\mathrm{f}}$ & 962 bp \\
\hline SCH3RAPD-R & TGCCGACTACGGTGTTCTTTATCCGT & $\begin{array}{l}\text { 21 st cycle: add extension of } \\
72^{\circ} \mathrm{C} ; 60 \mathrm{~s} \text { with increments } \\
\text { of } 5 \mathrm{~s} \text { for each cycle }(15 \mathrm{X})\end{array}$ & & \\
\hline
\end{tabular}

\footnotetext{
a General primers for A. pullulans required sequencing of the amplicon.

${ }^{\mathrm{b}}$ Westbridge Agricultural, Vista, CA.

c Annealing temperature, duration, and number of cycles to complete reaction.

${ }^{\mathrm{d}}$ From White et al. (1990).

e From Zalar et al. (2008).

${ }^{\mathrm{f}}$ Multiplex protocol adapted from Loncaric et al. (2008).
} 
iv) Blossom Protect only at $70 \%$ bloom; and v) two applications of Blossom Protect plus Buffer Protect (70\% and full bloom) with each treatment replicated four times in a randomized block design. As in 2015 , other trees in both orchards received additional fire blight suppression treatments, with a total of 16 of 70 pear trees and 16 of 65 apple trees receiving a Blossom Protect treatment. In the pear block, sprays were applied during the early morning on 29 March $(70 \%$ bloom) and 1 April (full bloom); treatments used in the apple orchard were applied on 6 April (70\% bloom) and 9 April (full bloom). At the time of spraying, Blossom Protect and/or Buffer Protect were premixed in 1-liter Nalgene bottles half-filled with water and shaken vigorously. The suspension was poured into a 1.5-liter volume of water in a hand-pumped backpack sprayer (model SG 20; STIHL Inc., Virginia Beach, VA) and sprayed onto the replicate trees under pressure (345 kPa) to near-runoff (3 liters per tree) with a hand wand attached to the sprayer.

After treatment, flowers were sampled at full bloom, petal-fall, and 7 to 10 days after petal-fall (2, 7, and 17 April, respectively, for pear; and 10, 12, and 19 April, respectively, for apple). Ten flowers with mature (dark) anthers were sampled randomly from each replicate tree (each flower from a different cluster) on each sampling date and washed individually using the previously described methods. Dilution plates were incubated for 3 days $\left(20^{\circ} \mathrm{C}\right)$, after which time colonies consistent with the sizes and morphologies of A. pullulans on reference controls were counted. For the full-bloom and petal-fall flower samples, when present, putative A. pullulans colonies were scraped from PDA dilution plates for treatments and subjected to PCR analysis.

In Wenatchee, the experiment was performed in two rows of a 1.4-ha orchard of 44-year-old apple cv. Red Delicious (on
MM.106 rootstock and spaced $3 \mathrm{~m}$ within rows by $7.5 \mathrm{~m}$ between rows) located at the Tree Fruit Research and Education Center of Washington State University. Single-tree plots were arranged in a randomized, complete block design and subjected to the aforementioned treatments. Within the rows, plot trees alternated with border trees; therefore, 8 of 53 trees in the plot area were treated with Blossom Protect. The same lots of Blossom Protect and Buffer Protect used in Corvallis were applied to trees at $80 \%$ bloom (10 April) as described. Flowers were sampled from trees at full bloom (13 April) and petal-fall (18 April) by randomly collecting 10 flower clusters from each replicate tree. Selected clusters were placed individually in 6- $\times 9-\mathrm{cm}$ paper coin envelopes. The full sample was packed lightly in a cardboard box and shipped to arrive in Corvallis the next day for processing. In the laboratory, a single flower was selected from each cluster (coin envelope) and washed in $1 \mathrm{ml}$ of SDW. After sonicating and vortexing, the plating of the wash was truncated compared with the process used in Corvallis. For Wenatchee samples, only the direct floral wash $(10 \mu \mathrm{l})$ was placed on PDA, and the drop was spread as widely as possible. From prior experience, we have found that, for shipped samples, the time lag between sampling and plating of the floral wash ( 24 to $48 \mathrm{~h}$ ) can influence the accuracy of population size estimates. Nonetheless, for the petal-fall sample, an estimate of the number of recovered A. pullulans colonies was obtained by scoring each plate as 'absent', 'low' (colonies individually countable; $<100$ per plate $=1 \times 10^{2}$ to $1 \times 10^{4} \mathrm{CFU}$ per flower), or 'high' (colonies individually uncountable; $>100$ per plate $=>1 \times$ $10^{4} \mathrm{CFU}$ per flower). As described, when present, putative $A$. pullulans colonies were scraped from plates and subjected to PCR analysis.

Specificity of Blossom Protect for fire blight control. In 2018 and 2019, trials were established for the older Bartlett pear block

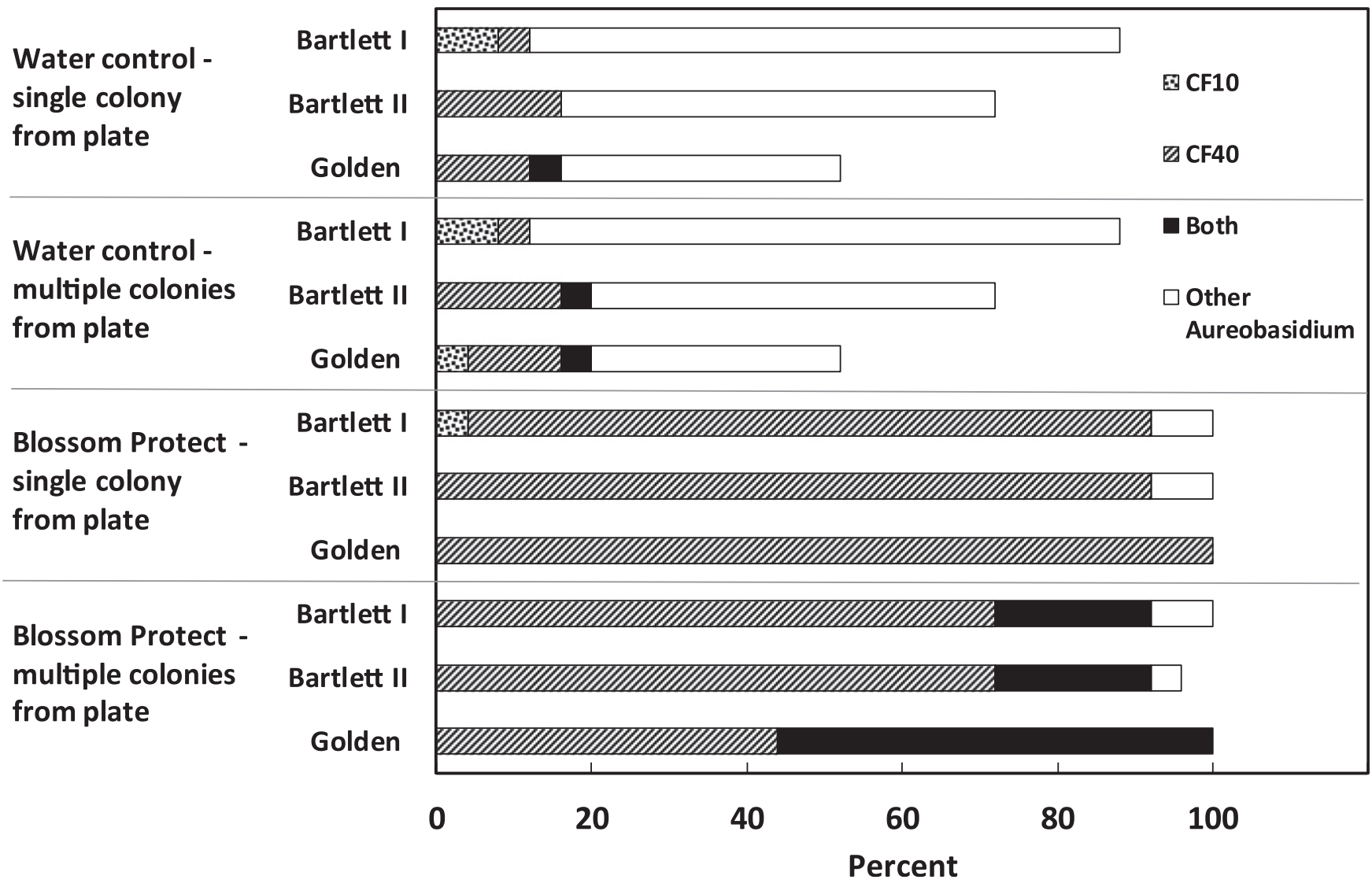

Fig. 1. Incidence (\%) of Aureobasidium pullulans in floral washes from 25 individual pear or apple flowers sampled near petal-fall after treatment of trees at $80 \%$ bloom with Blossom Protect (plus Buffer Protect) or water. Bars are subdivided by the incidence of detection of the specific strains of $A$. pullulans with Blossom Protect (CF10, dotted bar; CF40, striped bar), both of these strains (black bar), and other (indigenous) strains of $A$. pullulans (white bar). The Spring 2015 experiment was repeated in three orchards: 17- and 53-year-old 'Bartlett' pear (Bartlett I and Bartlett II, respectively), and 33-year-old 'Golden Delicious' apple. The sampling methods involved scraping with a flamed culture loop an apparently single colony of $A$. pullulans from a floral wash dilution cultured on potato dextrose agar or scraping multiple $A$. pullulans colonies from the dilution plate. Samples were subjected to PCR with primer sets (described in Table 1) 
and the Golden Delicious apple block at Corvallis to evaluate the effectiveness of Blossom Protect for fire blight suppression relative to other yeasts. Single-tree plots were arranged in a randomized block design with four replications of four or five treatments. Treatments were Blossom Protect $\left(1.6 \mathrm{~g} / \mathrm{liter}\right.$, for which the titer was $1 \times 10^{7}$ $\mathrm{CFU} / \mathrm{ml}$ of $A$. pullulans), a water-treated control, and several laboratoryincreased yeast isolates [a postharvest biocontrol strain of Cystofilobasidium infirmominiatum strain YY6 (Spotts et al. 2009), two local field isolates of $A$. pullulans (strains AP3 (used in pear only in 2018) and AP6 (used in 2019), and two local field isolates of Cryptococcus neoformans (strains C16 used in 2018 and C9 used in 2019)]. Local strains of $A$. pullulans and $C$. neoformans were isolated from flower washes during the 2016 experiment and identified by sequencing PCR amplicons from primers ITS and ELO2. To prepare yeast isolates for spraying, cultures were grown on PDA for 4 to 6 days $\left(20^{\circ} \mathrm{C}\right)$; then, they were scraped from the media surface and resuspended in SDW. Resulting cell suspensions were applied to trees at a concentration of $1 \times 10^{7} \mathrm{CFU} / \mathrm{ml}$.

In the orchard, treatments were sprayed during the early morning on days corresponding to $70 \%$ and full bloom: 9 and 14 April 2018 for pear; 25 and 26 April 2018 for apple; 18 and 20 April 2019 for pear; and 26 and 28 April 2019 for apple. Prior to spraying on trees, Buffer Protect (11.2 g/liter) was added to each yeast isolate suspension. In three of four trials, experimental trees were inoculated with Erwinia amylovora strain $153 \mathrm{~N}$ on the evening of the same day as the $70 \%$ bloom treatment; pear in 2018 was an exception and was inoculated on 12 April. Inoculum of the pathogen consisted of a suspension of freeze-dried cells of strain $153 \mathrm{~N}$ prepared at $1 \times 10^{6} \mathrm{CFU}$ per $\mathrm{ml}$ (Stockwell el al. 1998) that was fogged onto the trees with

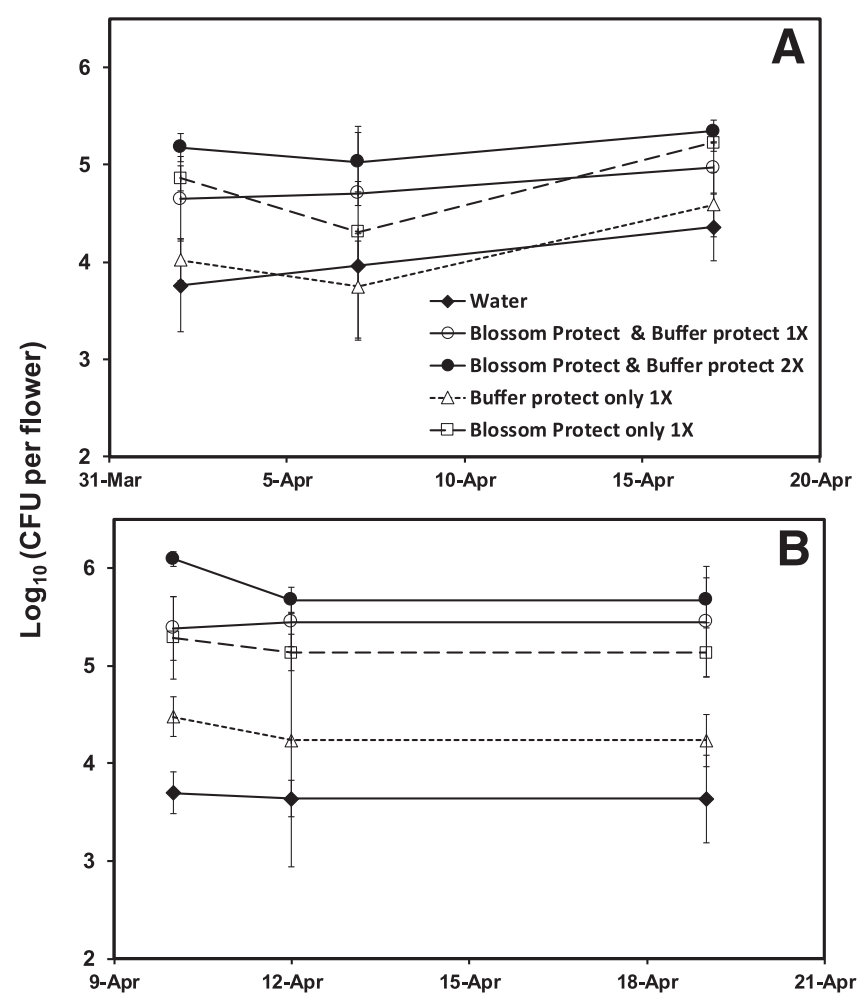

Fig. 2. $\log _{10}$ (population size) of Aureobasidium pullulans on A, Bartlett pear or B, Golden Delicious apple flowers treated once at $70 \%$ bloom with water (black diamond), Blossom Protect only (open square), Buffer Protect only (open triangle), or Blossom Protect plus Buffer Protect (once, open circle; twice, black circle) during Spring 2016 in experimental orchards located near Corvallis, OR. For the treatment that involved spraying with Blossom Protect plus Buffer Protect twice, the second spray date was 3 days after the first (full bloom). A. pullulans populations were determined by individually sampling 10 flowers from each replicate tree at full bloom, petal-fall, and 1-week after petal-fall. Each sample was washed in 1-ml of sterile distilled water, followed by dilution plating on potato dextrose agar amended with streptomycin sulfate. Data depict mean and standard error of four treatment replicates on each sampling date. a motorized 95-liter tank sprayer equipped with a hand wand (2 liters per tree) (Johnson and Temple 2013).

During bloom, yeast populations were measured by randomly sampling five flower clusters ( $\approx 25$ flowers, bulked) from each replicate tree. Bulked flower samples were washed and sonicated in $25-\mathrm{ml}$ of SDW; then, they were dilution-plated onto PDA. Sampling dates corresponded to full bloom (1 day after the second yeast treatment), petal-fall, and 4 to 7 days after petal-fall. In late May, the incidence of fire blight was determined by counting the number of blighted flower clusters on each tree during weekly inspections. Blighted clusters were cut from trees as they were counted.

Data analysis. The incidence of detection was calculated as the proportion of flowers positive for A. pullulans on each replicate tree of each treatment (the detection limit of the yeast plating assay was $100 \mathrm{CFU} /$ flower). Incidence values were further refined by the outcome of the PCR analyses: strain CF10 only; strain CF40 only; both strains detected; or 'other A. pullulans' detected. Replicate values for the incidence of detection were subjected to analysis of variance (ANOVA) (Analyze-It Software v. 3.0, Leeds, UK). However, first, the incidence data were examined for normality and, in most cases, transformed to the arcsine square root (x). The mean population size of $A$. pullulans for each replicate tree was obtained by averaging $\log _{10}$-transformed (CFU per flower) from each flower with positive detection. These data were graphed as treatment means (means of replicates), with time on the $x$-axis and mean $\log _{10}$ (population size) \pm the standard error of the mean (SEM) on the $y$-axis, and subjected to ANOVA after computing the summary statistic area under the population size curve $\left(A_{\text {pop }}\right)$, which represents an average weight for length of time between each sampling date:

$$
A_{\text {pop }}=\sum_{i=1}^{\eta-1}\left\{\left[\left(y_{i}+y_{i+1}\right) / 2\right] \cdot\left(t_{i+1}-t_{i}\right)\right\} /\left(t_{n}-t_{1}\right)
$$

where $y$ is the mean $\log _{10}$ (CFU/flower) for a replicate tree, $t$ is days after inoculation for the $i$ th sample date, and $n$ is the total number of sample dates.

The mean $\log _{10}$ (population size) was also used to summarize the yeast isolate trials in 2018 and 2019. The mean estimate for each replicate tree represented recovered yeast colonies with morphology and color consistent with the isolate sprayed on the tree. For the watertreated control, mean $\log _{10}$ (population size) was based on the total of all recovered yeast colonies. The incidence of fire blight infection was defined as the total number of blighted flower clusters divided by total number of clusters per tree, which were counted prior to bloom (Johnson and Temple 2013). Each of these variables were subjected to ANOVA as described.

\section{Results}

Preliminary analyses. InstaGene Matrix was selected as the method of DNA extraction after comparing this approach to the cost (time and expense) and the DNA yield and purity obtained with the other methods (data not shown) (Ciardo et al. 2007, 2010). Twelve isolates of A. pullulans from each of three packages of Blossom Protect yielded ratios of CF10 to CF40 of 4:8, 6:6, and 5:7. PCR amplicons from strain-specific primers SCAR6 and SCH3RAPD (Table 1) were stable over 10 sequential transfers of the isolates on PDA.

For strain-specific identification of A. pullulans from floral washes spread on PDA, the scraping of multiple colonies for PCR analysis provided more information than the selection of an apparent single colony (Fig. 1). For flowers treated with Blossom Protect, A. pullulans was recovered from all sampled flowers except one (74 of 75 flowers). Using the single colony method, strain CF40 was associated with $93 \%$ of the flowers; the remaining $7 \%$ were identified as other A. pullulans. CF10 was not detected. When multiple colonies were scraped from the medium, CF40 was detected on $95 \%$ of flowers, and CF10 was coincident with CF40 on $32 \%$ of flowers. For the water control, A. pullulans was detected on $70 \%$ of flowers, but $77 \%$ of these detections were identified as other A. pullulans. CF10 and 
CF40 were each detected individually on 3 and $11 \%$ of water-treated flowers, respectively, and both strains were detected on $2 \%$ of watertreated flowers.

Corvallis orchard experiments. In 2016, the total April rainfall for Corvallis was $76 \mathrm{~mm}$, and the average daily high temperature was $18.9^{\circ} \mathrm{C}$. Two periods of warmer weather coincided with pear and apple bloom: 6 to 9 April, when daily high temperatures averaged $23^{\circ} \mathrm{C}$, and 16 to 21 April, when daily high temperatures averaged $25^{\circ} \mathrm{C}$.

A. pullulans was recovered from most $(>90 \%)$ Bartlett pear and Golden Delicious apple flowers sampled from experimental trees at the Corvallis location, regardless of whether the trees were treated with Blossom Protect, and the incidence of detection of A. pullulans on flowers did not differ significantly among the treatments $(P>0.05)$. Nevertheless, population size estimates of $A$. pullulans on the flowers at full bloom, petal-fall, and 1 week after petal-fall were correlated with the number of times Blossom Protect was applied to the trees (Fig. 2). The treatment consisting of Blossom Protect plus Buffer Protect applied twice showed mean A. pullulans population sizes of $\geq 1 \times 10^{5} \mathrm{CFU} /$ flower for both pear and apple, whereas the population size estimates after one application of the biocontrol product were one-quarter to one-half of a log unit lower than that on flowers from trees treated twice. Population sizes of A. pullulans on trees that received either water or Buffer Protect averaged $1 \times$ $10^{4} \mathrm{CFU} /$ flower, which was 1 to $2 \log$ units smaller than that on trees treated once with Blossom Protect. An ANOVA of the relative area under the population size curve $\left(A_{\text {pop }}\right)$ resulted in least significant difference values of $0.21 \log _{10}$ (CFU/flower) for pear and $0.25 \log _{10}$ (CFU/flower) for apple, which indicated significant differences $(P \leq 0.05)$ in $A$. pullulans population sizes among trees that received Blossom Protect compared with those that did not.

For putative A. pullulans colonies sampled from dilution plates and subjected to PCR analysis, sequenced amplicons from ITS and
ELO2 primers nearly always corresponded ( $>98 \%)$. Additionally, if the SCAR6 or SCH3RAPD primers were positive for strains $\mathrm{CF} 10$ or CF40, then sequenced amplicons from at least one of the general primers yielded an identification of A. pullulans. SCAR6 and SCH3RAPD primers detected differences in the specific detection of $\mathrm{CF} 10$ and $\mathrm{CF} 40$ that were attributable to the treatment the trees received (Fig. 3A and B). For example, if a flower was from a tree treated with Blossom Protect, then $95 \%$ of flowers had a positive reaction with these primer sets (Fig. 3). For trees not treated with Blossom Protect (water or Buffer Protect only), the combined incidence rates of detection of CF10 and CF40 were $21 \%$ for Bartlett pear and $15 \%$ for Golden Delicious apple, which were significantly smaller $(P \leq 0.05)$ than observed for trees sprayed with Blossom Protect. As in the preliminary experiments, on trees treated with Blossom Protect, CF40 was detected more frequently than CF10 (CF40 detection: $92 \%$ on pear and $64 \%$ on apple; CF10 detection: $62 \%$ on pear and $47 \%$ on apple). During both experiments, differences in the incidence rates of detection of CF10 or CF40 did not differ significantly $(P>0.05)$ among Blossom Protect treatments with or without Buffer Protect or among the water control and Buffer Protect only (Fig. 3).

Wenatchee orchard experiment. The total rainfall for Wenatchee in April 2016 was $13 \mathrm{~mm}$, and the average daily high temperature was $21.8^{\circ} \mathrm{C}$. Two periods of warmer weather coincided with apple bloom: 7 to 11 April, when daily high temperatures averaged $25^{\circ} \mathrm{C}$, and 16 to 21 April, when daily high temperatures averaged $27^{\circ} \mathrm{C}$.

Compared with the Corvallis experiments, the primary difference observed in Wenatchee was that A. pullulans was not as frequently detected on flowers sampled from the water only of Buffer Protect only treatments. At full bloom, A. pullulans was detected on only $23 \%$ of Red Delicious flowers sampled from the water control
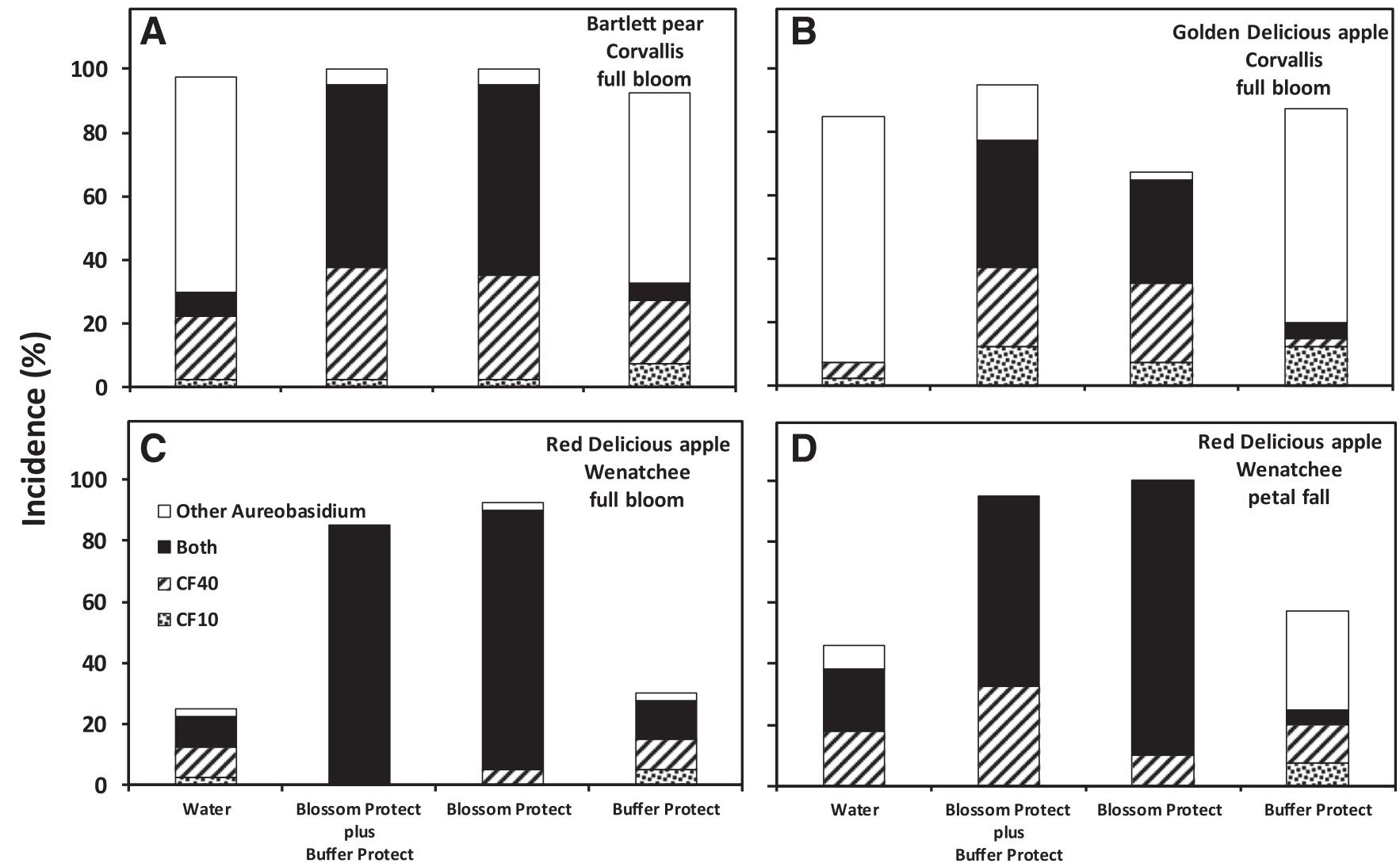

Fig. 3. Incidence of detection of Aureobasidium pullulans on pear and apple flowers after treatment with Blossom Protect and/or Buffer Protect once at 70 to $80 \%$ bloom during Spring 2016 in experimental orchards located near A and B, Corvallis, OR and C and D, Wenatchee, WA. Bars are subdivided by the incidence of detection of the specific strains of A. pullulans with Blossom Protect (CF10, dotted bar; CF40, striped bar), both of these strains (black bar), and other (indigenous) strains of $A$. pullulans (white bar). Data were obtained by plating the wash from each of 40 flowers (10 per replicate) on potato dextrose agar, followed by subjecting a plate scraping of multiple recovered colonies of $A$. pullulans to DNA extraction and identification by PCR analysis with primer sets (described in Table 1). 
treatment and on only $28 \%$ of flowers from the Buffer Protect only treatment group (Fig. 3C). Most of the differences between locations were attributable to reduced detection of other A. pullulans on flowers from trees not treated with Blossom Protect, not to differences in the detection of CF10 or CF40 (Fig. 3). The incidence of detection of A. pullulans on flowers differed significantly $(P \leq 0.05)$ among the treatments that received Blossom Protect compared with those that did not. In contrast, the incidence of detection of A. pullulans did not differ significantly $(P>0.05)$ among Blossom Protect treatments with or without Buffer Protect or among the water control only and Buffer Protect only treatments. Similar to Corvallis, the incidence of CF10 and/or CF40 on flowers from Wenatchee exceeded $90 \%$ on trees treated with Blossom Protect $(>90 \%)$, with $\mathrm{CF} 40$ detected more often than CF10 (93 versus $80 \%$ of flowers, respectively). Also consistent with the Corvallis trial, at petal-fall, 69\% of flowers sampled from Blossom Protect-treated trees in Wenatchee had an estimated $A$. pullulans population size $\geq 1 \times 10^{4} \mathrm{CFU} /$ flower. In contrast, for trees that were treated with water or Buffer Protect, only $32 \%$ of flowers on which A. pullulans was detected had an estimated population $\geq 1 \times 10^{4} \mathrm{CFU} /$ flower, with the remaining $68 \%$ of positive detections having a population size between $1 \times 10^{2}$ and $1 \times 10^{4}$ CFU/flower.

Specificity of Blossom Protect for fire blight control. Yeasts were readily recovered from flowers sampled from yeast-treated trees (Fig. 4), with the species that was applied to the trees being the dominant species recovered on the dilution plates. Moreover, regardless of the isolate, each yeast generally attained population sizes exceeding $1 \times 10^{4} \mathrm{CFU} /$ flower (as summarized by $\mathrm{A}_{\text {pop }}$ ), and these populations were significantly larger $(P \leq 0.05)$ than the total yeast population size on the water-treated controls. Use of the bulked 25-flower samples from each replicate tree resulted in small sampling variations among similarly treated experimental replicates; consequently, differences in $\mathrm{A}_{\text {pop }}$ were observed among yeast treatments.
For example, for both pear and apple in 2018, trees treated with C. infirmominiatum strain YY6 had significantly larger populations $(P$ $\leq 0.05$ ) of this yeast on flowers compared with the A. pullulans populations measured on flowers treated with Blossom Protect (Fig. 4A and C). For all trials, A. pullulans populations on Blossom Protecttreated trees were either statistically similar to or smaller than population sizes measured for the other yeast treatments. The exception was apple in 2019 , for which the A. pullulans population measured on Blossom Protect-treated trees was significantly greater $(P<$ 0.05 ) than the A. pullulans population on trees treated with local isolate AP6 of this fungus (Fig. 4D).

Regarding fire blight, all yeast treatments resulted in a lower incidence of infection than the water treatment (control) (Fig. 5). Additionally, in each of the trials, fire blight suppression by Blossom Protect was numerically superior to disease suppression by the other yeast isolates. For each trial, the ANOVA resulted in significant differences $(P \leq 0.05)$ in the incidence of infection among treatments, with Blossom Protect being significantly superior $(P \leq 0.05)$ to each of the other yeast isolates in two of the trials (Fig. 5A and C). When averaged over trials, two applications of Blossom Protect (plus Buffer Protect) provided $81 \%$ (SE $\pm 5 \%$ ) control of fire blight. In contrast, the next most suppressive treatment, C. infirmominiatum strain YY6 (plus Buffer Protect), provided 58\% (SE \pm 13\%) control.

\section{Discussion}

The biological product Blossom Protect has become an important component of integrated nonantibiotic control of fire blight in pome fruit production areas of the Pacific Northwest. Its adoption for the suppression of fire blight has been rapid; it was first registered in the United States in 2012, with only a minimal literature base regarding the use of $A$. pullulans for this purpose. Consequently, our goals during this study were to evaluate specific detection of $A$. pullulans strains CF10 and CF40 from an orchard environment, examine the
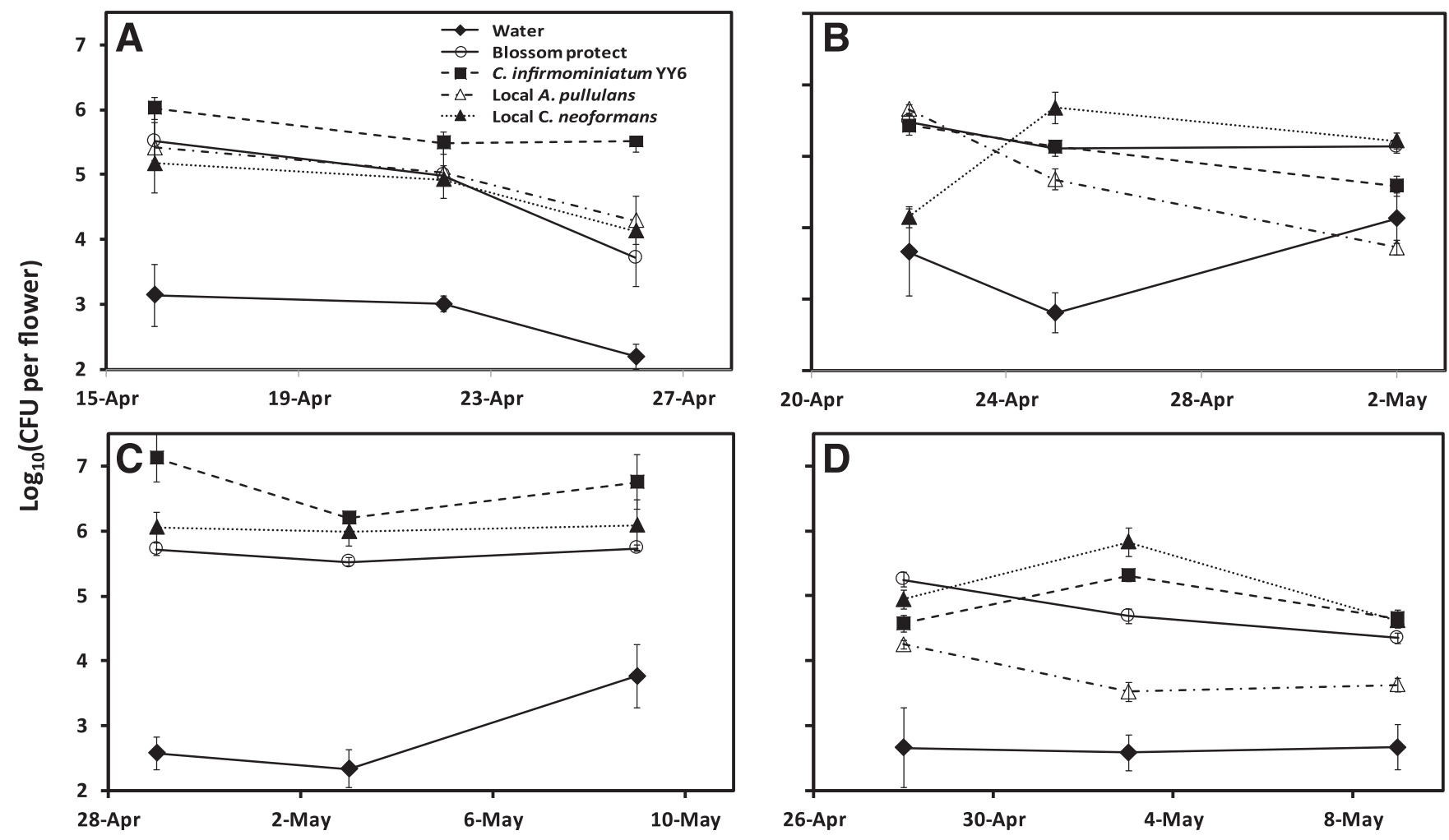

Fig. 4. $\log _{10}$ (population size) of yeast isolates on $A$ and B, Bartlett pear or $C$ and D, Golden Delicious apple flowers sprayed at $70 \%$ and full bloom during Spring 2018 (left panels) and Spring 2019 (right panels) in experimental orchards located near Corvallis, OR. Treatments were water (black diamond), Blossom Protect (open circle), Cystofilobasidium infirmominiatum YY6 (black square), two local field isolates of A. pullulans, AP3 (2018) and AP6 (2019) (open triangle), and two local field isolates, C16 (2018) and C9 (2019), of Cryptococcus neoformans (black triangle); all yeast treatments were amended with Buffer Protect. Yeast population sizes were determined by bulk sampling 25 flower clusters from each replicate tree at full bloom, petal-fall, and 4 to 7 days after petal-fall. Each sample was washed in 25-ml of sterile distilled water followed by dilution plating on potato dextrose agar amended with streptomycin sulfate. Data depict mean and standard error of four treatment replicates on each sampling date. 
role of the companion citrate-based buffer in A. pullulans establishment, contrast differences in A. pullulans population sizes among treated and nontreated flowers, observe potential secondary colonization of nontreated flowers, and determine whether strains CF10 and CF40 show specificity for fire blight suppression.

The specific PCR primers for the detection of A. pullulans strains CF40 and CF10 provided data regarding their establishment on flowers relative to indigenous strains of this organism. Both CF40 and CF10 appeared to be good colonists of pome trees treated directly with Blossom Protect, as evidenced by the high proportions of flowers from which at least one of these strains was detected and the 10-fold larger population size of A. pullulans on trees treated with Blossom Protect compared with those that were not treated with the yeast. In each experiment, strain CF40 was isolated from flowers more frequently than $\mathrm{CF} 10$, but this was also observed when we isolated A. pullulans from commercial packages of Blossom Protect. Understanding the relative contributions of CF10 and CF40 to the efficacy of Blossom Protect should be an objective of future research. Based on the general primers, ITS and ELO2, we concur with the results of previous reports (McGrath and Andrews 2006; Pusey et al. 2009) that found A. pullulans to be a common organism on pear and apple trees. This was especially true in the Corvallis environment, which has a wetter spring season than Wenatchee. A comparison of the two environments in which Blossom Protect was sprayed showed that there was no evidence indicating that establishment of $\mathrm{CF} 10$ or $\mathrm{CF} 40$ on flowers was hampered by the more abundant indigenous A. pullulans at the Corvallis location.

The observation of a high proportion of flowers from control trees harboring indigenous A. pullulans in Corvallis raised the question about the specificity of CF10 and CF40 for fire blight suppression. Numerous strains of A. pullulans have been shown to suppress fungal fruit rots (Leibinger et al. 1997; Mari et al. 2012; Zhang et al. 2010), but only strains CF10 and CF40 have been demonstrated to control fire blight (Johnson and Temple 2013; Kunz et al. 2008). Therefore, in 2018 and 2019, various yeast isolates were sprayed on pome trees to attempt to determine whether observed biocontrol of fire blight is simply a function of yeast population size (i.e., of any yeast), or if CF10 and CF40, strains selected originally for their ability to suppress fungal fruit rots of apple, also possess a superior ability to suppress fire blight. Like CF10 and CF40, our chosen yeast comparators were isolated originally from pome flowers or fruits and could attain high populations when sprayed on pear and apple flowers; they also contributed a degree of fire blight control. Beyond this, however, isolates CF10 and CF40 (albeit from formulated products as opposed to laboratory-grown cultures) attained a level of control that was superior to that of other yeast isolates. This observation suggested that future research should be directed at understanding this superiority. Related to this, we have observed that pome flowers colonized by Blossom Protect strains of $A$. pullulans are not greatly suppressive of epiphytic populations of $E$. amylovora, but fire blight is controlled (K. Johnson unpublished data). This may indicate that the apparent mechanism of biocontrol possessed by CF10 and/or CF40 is more complex than a simple explanation of superior competitive exclusion.

In addition to antagonizing plant pathogens, A. pullulans has been implicated as one of the causes of russeting of pome fruits (Kunz et al. 2008; Matteson-Heidenreich et al. 1997; Spotts and Cervantes 2002). Russeting is a market-devaluing disorder of the fruit cuticle, and the risk is highest in the month following bloom (Musacchi and Serra 2018). Moisture on the fruit surface during this period exacerbates this risk; consequently, fruit russeting is observed more commonly in a wetter postbloom environment. In fact, our experiments in Corvallis with Blossom Protect have shown an association between the use of this material and fruit russeting on pear and, to a lesser degree, on apple if frequent rains occur in late April (K. Johnson, unpublished data). Furthermore, russeting of apple fruit after the application of Blossom Protect has been observed in Pennsylvania (Peter and Lehman 2017). In contrast, for the arid regions of central Washington, where suppression of fire blight with Blossom Protect has been widely implemented, russeting of fruit caused by A. pullulans is not typically observed. In a study of indigenous A. pullulans, Spotts and Cervantes (2002) concluded that this yeast was not a major contributor to fruit russeting of d'Anjou pear fruit in Oregon's semi-arid Hood River valley. They based this conclusion on population sizes of A. pullulans observed in flowers colonized naturally compared with populations measured after inoculation. With the inoculation treatments described by Spotts and Cervantes (2002), however, russeting of pear fruit with A. pullulans was occasionally enhanced by treating flowers with spore concentrations similar to the concentration in a spray tank of Blossom Protect.

Our study also included treatments to contrast the use of Blossom Protect with and without its companion buffer, Buffer Protect, and to compare the use of water only (control) and the use of Buffer Protect only (control). In a spray tank, Buffer Protect has a relatively low $\mathrm{pH}$ ( $\mathrm{pH}$ 3.6); however, after spraying, the $\mathrm{pH}$ of floral surfaces is reduced to a lesser degree (to a $\mathrm{pH}$ of 5.4 to 5.7 compared with a nontreated $\mathrm{pH}$ of 5.9 to 6.1) (S. Uppala and K. Johnson, unpublished data). We did not observe any effects of Buffer Protect on the primary establishment of CF10 and CF40 on flowers or on yeast colonization of flowers on trees that received only the buffer compared with those sprayed with water. Kunz (2004) speculated that acidification of host surfaces is at least partially responsible for the observed suppression of E. amylovora, with the rationale that the initial low $\mathrm{pH}$ environment created by the buffer suppresses the epiphytic population of the pathogens, thus giving A. pullulans more time to colonize flowers prior to the resumption of pathogen growth.

The degree of secondary colonization of nontreated flowers is important for determining recommendations regarding how to use a biological agent for fire blight control, including frequency of application of the biological agent and whether the pattern of spraying can be modified (e.g., alternate-row spraying versus all-row spraying). Most secondary colonization of previously untreated flowers by introduced biocontrol agents is attributable to dispersal of the microbes via pollinating insects (Johnson et al. 1993; Johnson

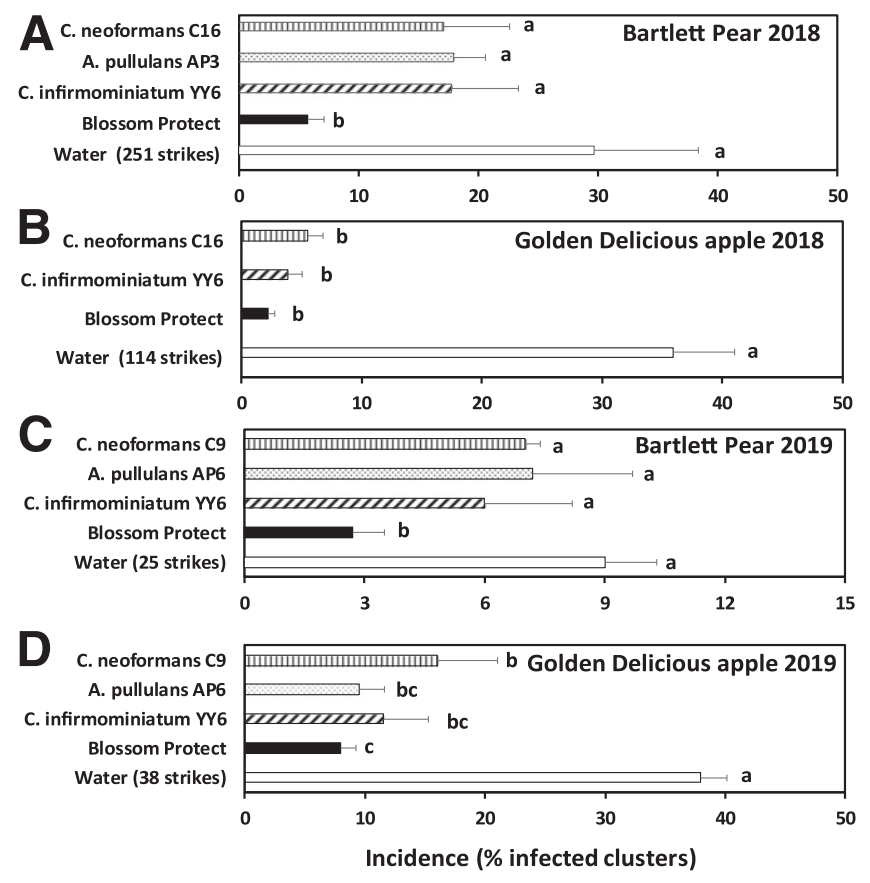

Fig. 5. Effects of yeast plus Buffer Protect treatments on the incidence of fire blight infection in 'Bartlett' pear and 'Golden Delicious' apple orchards located near Corvallis, OR in April and May 2018 (A and B) and 2019 (C and D). Yeast (or water) treatments were arranged in a randomized block design with four replications and sprayed at $80 \%$ and full bloom. The fire blight pathogen was inoculated on trees during the evening between the two treatment dates. Incidence of infection was defined as infected flower clusters divided by total flower clusters on a tree. Absolute number of infections per tree (strikes) for the water controls are shown in parentheses. Within a panel, bars labeled with a different lowercase letter indicate a significant difference in the arcsine square root-transformed disease incidence data according to Fischer's protected least significant difference at $P=$ 0.05 ; error bars associated with each point represent one standard error of the mean. 
and Stockwell 1998; Lindow and Suslow (2003), Nuclo et al. 1998; Pusey 2002). In previous studies of secondary colonization of flowers by introduced Gram-negative bacterial antagonists of the fire blight pathogen, the degree to which a bacterial agent was detected on nontreated trees was generally greater than that we observed for A. pullulans strains CF10 and CF40. For example, with Pantoea agglomerans strain C9-1, Johnson et al. (2000) observed that pear and apple trees up to $15 \mathrm{~m}$ from treated trees had high proportions of blossoms colonized by the introduced bacterium. Furthermore, within a randomized block design similar to those we used, Pusey (2002) observed high rates of dispersal of $P$. agglomerans strain C9-1 and P. fluorescens strain A506 from treated to nontreated apple trees (70 to $90 \%$ incidence on nontreated flowers); these were greatly reduced if the nontreated tree was surrounded by a plastic film enclosure. A simple explanation for why a bacterium may disperse better than a yeast is that population size of the bacterium at the source (a colonized flower) is typically 1 to $2 \log$ units larger; therefore, the more abundant microbe is moved more readily by insects. Nonetheless, other factors could potentially contribute to bacteria dispersing faster than yeasts, including differences in reproductive rates and in the floral surfaces where the microbes reside.

Because of lower incidences of detection and lower population sizes of Blossom Protect strains CF10 and CF40 on nontreated trees compared with treated trees, and because of the apparent need for a large yeast population to achieve fire blight suppression, we recommend that organic orchardists should apply one complete (all rows) treatment of Blossom Protect plus Buffer Protect at 70 to $80 \%$ bloom as part of a comprehensive, integrated fire blight management program. This timing of treatment at 70 to $80 \%$ bloom does not conflict with other required treatments in the orchard (e.g., sprays of lime sulfur for crop load thinning) (Johnson and Temple 2013). At 70 to $80 \%$ bloom, the application is early enough that good establishment and colonization by $\mathrm{CF} 10$ and $\mathrm{CF} 40$ can be expected and late enough that most flowers will be treated directly with the biological agent.

\section{Acknowledgment}

The authors thank Esteban Gutierrez and Benjamin Walsh for technical assistance.

\section{Literature Cited}

Ciardo, D., Lucke, K., Imhof, A., Bloemberg, G., and Böttger, E. 2010. Systematic internal transcribed spacer sequence analysis for identification of clinical mold isolates in diagnostic mycology: a 5-Year Study. J. Clin. Microbiol. 48:2809-2813.

Ciardo, D. E., Schär, G., Altwegg, M., Böttger, E. C., and Bosshard, P. P. 2007. Identification of moulds in the diagnostic laboratory-an algorithm implementing molecular and phenotypic methods. Diagn. Microbiol. Infect. Dis. 59:49-60.

Johnson, K. B., and Stockwell, V. O. 1998. Management of fire blight: A case study in microbial ecology. Annu. Rev. Phytopathol. 36:227-248.

Johnson, K. B., Stockwell, V. O., Burgett, D. M., Sugar, D., and Loper, J. E. 1993. Dispersal of Erwinia amylovora and Pseudomonas fluorescens by honey bees from hives to apple and pear blossoms. Phytopathology 83:478-484.

Johnson, K. B., Stockwell, V. O., and Sugar, D. 2000. Assessment of environmental factors influencing growth and spread of Pantoea agglomerans on and among blossoms of apple and pear. Phytopathology 90:1285-1294.

Johnson, K. B., and Temple, T. N. 2013. Evaluation of strategies for fire blight control in organic pome fruit without antibiotics. Plant Dis. 97:402-409.

Johnson, K. B., Temple, T. N., Elkins, R. B., and Smith, T. J. 2014. Strategy for nonantibiotic fire blight control in U.S.-grown organic fruit. Acta Hortic.: 93-100 (ISHS).

Kunz, S. 2004. Development of "Blossom-Protect" - a yeast preparation for the reduction of blossom infections by fire blight. Pages 108-114 in: Ecofruit - 11th International Conference on Cultivation Technique and
Phytopathological Problems in Organic Fruit Growing. M. Boos (ed.). Fördergemeinschaft Ökologischer Obstbau e.V., Weinsberg, Germany.

Kunz, S., Schmitt, A., and Haug, P. 2008. Field testing of strategies for fire blight in organic fruit growing. Pages 299-305 in: Ecofruit - 13th International Conference on Cultivation Technique and Phytopathological Problems in Organic Fruit Growing. M. Boos (ed.).. Fördergemeinschaft Ökologischer Obstbau e.V., Weinsberg, Germany.

Leibinger, W., Breuker, B., Hahn, M., and Mendgen, K. 1997. Control of postharvest pathogens and colonization of the apples surface by antagonistic microorganisms in the field. Phytopathology 87:1103-1110.

Lindow, S. E., and Suslow, T. V. 2003. Temporal dynamics of the biocontrol agent Pseudomonas fluorescens strain A506 in flowers in inoculated pear trees. Phytopathology 93:727-737.

Loncaric, I., Donat, C., Antlinger, B., Oberlerchner, J. T., Heissenberger, B., and Moosbeckhofer, R. 2008. Strain-specific detection of two Aureobasidium pullulans strains, fungal biocontrol agents of fire blight by new, developed multiplex-PCR. J. Appl. Microbiol. 104:1433-1441.

Mari, M., Martini, C., Guidarelli, M., and Neri, F. 2012. Postharvest biocontrol of Monilinia laxa, Monilinia fructicola and Monilinia fructigena on stone fruit by two Aureobasidium pullulans strains. Biol. Control 60:132-140.

Matteson-Heidenreich, M. C., Corral-Garcia, M. R., Momol, E. A., and Burr, T. J. 1997. Russet of apple fruit caused by Aureobasidium pullulans and Rhodotorula glutinis. Plant Dis. 81:337-342.

McGrath, M. J., and Andrews, J. H. 2006. Temporal changes in microscale colonization of the phylloplane by Aureobasidium pullulans. Appl. Environ. Microbiol. 72:6234-6241.

Musacchi, S., and Serra, S. 2018. Apple fruit quality: Overview of pre-harvest factors. Sci. Hortic. (Amsterdam) 234:409-430.

Nuclo, R. L., Johnson, K. B., Stockwell, V. O., and Sugar, D. 1998. Secondary colonization of pear blossoms by two bacterial antagonists of the fire blight pathogen. Plant Dis. 82:661-668.

Peter, K. A., and Lehman, B. 2017. Evaluation of conventional and biopesticide programs to mitigate the blossom blight phase of fire blight on 'Gala' apple trees in Pennsylvania, 2016. Plant Dis. Manage. Rep. 11:PF019.

Pusey, P. L. 2002. Biological control agents for fire blight of apple compared under conditions limiting natural dispersal. Plant Dis. 86:639-644.

Pusey, P. L., and Smith, T. J. 2008. Relation of apple flower age to infection of hypanthium by Erwinia amylovora. Plant Dis. 92:137-142.

Pusey, P. L., Stockwell, V. O., and Mazzola, M. 2009. Epiphytic bacteria and yeasts on apple blossoms and their potential as antagonists of Erwinia amylovora. Phytopathology 99:571-581.

Spotts, R. A., and Cervantes, L. A. 2002. Involvement of Aureobasidium pullulans and Rhodotorula glutinis in russet of d'Anjou pear fruit. Plant Dis. 86:625-628.

Spotts, R. A., Wallis, K. M., Serdani, M., O'Gorman, D. T., and Sholberg, P. L. 2009. Real time polymerase chain reaction for rapid and quantitative determination of Cystofilobasidium infirmominiatum on the surfaces of apple, pear, and sweet cherry fruit. Postharvest Biol. Technol. 51:227-231

Stockwell, V. O., Johnson, K. B., and Loper, J. E. 1998. Establishment of bacterial antagonists of Erwinia amylovora on pear and apple blossoms as influenced by inoculum preparation. Phytopathology 88:506-513.

Thomson, S. V. 2000. Epidemiology of fire blight, Pages 9-36 in: Fire Blight: The Disease and Its Causative Agent, Erwinia amylovora. J. L. Vanneste (ed.). CAB International, London.

Van der Zwet, T., and Beer, S. V. 1995. Fire blight - Its nature, prevention, and control: A practical guide to integrated disease management. U.S. Dept. Agric. Info. Bull. 631.

White, T. J., Bruns, T., Lee, S., and Taylor, J. 1990. Amplification and direct sequencing of fungal ribosomal RNA genes for phylogenetics, Pages 315-322 in: PCR Protocols: a guide to methods and applications. M. A Innis, D. H. Gelfand, J. J. Sninsky, and T. J. White (eds.). Academic Press, New York.

Zalar, P., Gostinčar, C., de Hoog, G. S., Uršič, V., Sudhadham, M., and GundeCimerman, N. 2008. Redefinition of Aureobasidium pullulans and its varieties. Stud. Mycol. 61:21-38.

Zhang, D., Spadaro, D., Garibaldi, A., and Gullino, M. L. 2010. Efficacy of the antagonist Aureobasidium pullulans PL5 against postharvest pathogens of peach, apple and plum and its modes of action. Biol. Control 54:172-180. 